\title{
Marco Stupazzoni, « Honoré de Balzac e l'indice dei libri proibiti. Il Decretum del 16 settembre 1841. Documenti inediti »
}

\section{Franca Zanelli Quarantini}

\author{
(2) OpenEdition \\ Journals \\ Edizione digitale \\ URL: http://journals.openedition.org/studifrancesi/30447 \\ DOI: $10.4000 /$ studifrancesi.30447 \\ ISSN: 2421-5856 \\ Editore \\ Rosenberg \& Sellier

\section{Edizione cartacea} \\ Data di pubblicazione: 1 avril 2006 \\ Paginazione: 171-172 \\ ISSN: 0039-2944 \\ Notizia bibliografica digitale \\ Franca Zanelli Quarantini, «Marco Stupazzoni, « Honoré de Balzac e l'indice dei libri proibiti. II Decretum \\ del 16 settembre 1841. Documenti inediti »», Studi Francesi [Online], 148 (XLX | I) | 2006, online dal 30 \\ novembre 2015, consultato il 19 avril 2021. URL: http://journals.openedition.org/studifrancesi/30447 ; \\ DOI: https://doi.org/10.4000/studifrancesi.30447
}

Questo documento è stato generato automaticamente il 19 avril 2021.

\section{cc) (†) $\odot$}

Studi Francesi è distribuita con Licenza Creative Commons Attribuzione - Non commerciale - Non opere derivate 4.0 Internazionale. 


\title{
Marco Stupazzoni, « Honoré de Balzac e l'indice dei libri proibiti. Il Decretum del 16 settembre 1841. Documenti inediti »
}

\author{
Franca Zanelli Quarantini
}

\section{NOTIZIA}

MARCO STUPAZZONI, « Honoré de Balzac e l'indice dei libri proibiti. Il Decretum del 16 settembre 1841. Documenti inediti », in « Quaderni del C.R.I.E.R. », supplemento al n5, 2003, pp. 5-31.

1 «Il nome del Sig. de Balzac è divenuto famoso nella Francia, e nell'Europa per le sue empie e scandalose produzioni [...] piene di oscenità e laidezza »; sulla base di questa $\mathrm{e}$ altre motivazioni similari il 16 settembre 1841 vennero incluse nell'Index librorum proibitorum otto opere balzachiane - Le Lys dans la vallée, La Physiologie du mariage, Les Contes drolatiques, L'Israélite, L'Excommunié, Le Livre mystique (ossia Les Proscrits, Louis Lambert, Séraphita), i Nouveaux Contes philosophiques (e più precisamente Maître Cornélius, L'Auberge rouge e Louis Lambert) e i Contes bruns. Eterogeneo e diseguale, l'elenco lascia già intuire l'angustia dei limiti culturali entro cui operarono i canonici Bighi, Tizzani, Zecchinelli e Cannella, incaricati di stendere le singole relazioni che, lette oggi, stupiscono talvolta per ingenuità, più spesso per l'ostinazione con cui viene negato alla letteratura, indipendentemente da finalità edificanti, il seppur minimo spazio di libertà creativa; è quanto attesta per esempio questo drastico rilievo di "genere", stilato a Parigi dal canonico Garibaldi: "Le opere di Balzac e di Georges Sand [...] sono in generale molto cattive, almeno per quanto ne sento dire da tutti. Io non le ho mai lette, sia perché trattasi di libri di lor natura non istruttivi (romanzi), sia perché i libri di 
questa specie sono qui così frequenti e così numerosi, che soltanto per percorrerli vi vorrebbe un tempo infinito » (p. 21).

2 È insomma lecito qua e là sorridere, specie nel leggere che «l'autore lussureggia nella stessa lussuria " (dal giudizio dell'abate Tizzani sui Contes drolatiques, p. 105); oppure che in un testo minore, ma dal titolo infido come L'Israélite, «si prende la S. Scrittura per ischerzo, [...] s'insinua alle innocenti donzelle la fuga dai genitori per unirsi ai loro amanti, [...] si dipinge un Vescovo fautore della sua religione per solo interesse, in una parola tutto cospira al disprezzo della religione e all'eccitamento di voluttuose passioni »(p.129). Resta che la volontà repressiva quale si manifesta attraverso le parole della Sacra Congregazione dell'Indice segnala in modo palpabile l'antagonismo in atto nell'Ottocento tra il potere temporale e il ruolo dell'artista, tra la secolare diffidenza della Chiesa di Roma per il "nuovo" e ogni atteggiamento intellettuale in grado di sbilanciare il difficile equilibro tra vita morale e vita sociale; è quanto si evince dalle parole dell'allora pontefice Gregorio XVI, che nell'Enciclica Mirari vos del 1832 lamenta «il funestissimo pervertimento dei costumi», insieme all'«infernale cospirazione degli empi », il tutto nel disprezzo della "santità delle cose sacre, e [dell']augusta maestà del divin culto » (p. 30). Ciò portò conseguentemente alla messa al bando di gran parte degli scrittori più in auge in Francia: da Hugo, colpevole di aver profanato un luogo sacro intitolando il suo romanzo Notre-Dame de Paris, a Lamartine, autore della Chute d'un ange e di Jocelyn; da George Sand, che la Curia sospettò ispirata dal «troppo famoso Ab. de Lammenais », allo Stendhal di Rome, Naples et Florence en 1817.

3 Pur dichiarandosi cattolico e legittimista, neppure Balzac sfuggì alle maglie della censura romana, più che mai ostile alle appassionate tematiche intorno all'amor proibito, presenti per esempio nel Lys - «sarebbe desiderabile che una tale opera non solo venisse proscritta, ma che se ne perdesse affatto la memoria », scrive al riguardo il canonico Bighi (p. 77) - e non meno ostile alla visione spiritualistica del romanziere intrisa di dottrina swedenborghiana e spinozismo - culminante in quella Séraphita ove, per il gesuita Zecchinelli, l'autore "non fa che diffondersi in vane pitture poetiche, mentre intanto seduce col fiorito dello stile, e trascina i miseri imperiti leggitori, amanti del nuovo, che sono i più, nell'orribile abisso del dubbio, del disprezzo per la religione, dell'amor del meraviglioso, della presunzione del poter da sé medesimi aprirsi la strada ad uno stato migliore » (p. 98).

Non è forse a tutti noto che soltanto a partire dal 22 gennaio 1998, con la solenne apertura ufficiale degli Archivi del Sant'Uffizio Romano, è divenuto possibile consultare i documenti dell'Index. Stupazzoni, che da decenni intrattiene con Balzac un'intensa e fertile frequentazione, in questo lavoro utilissimo non si limita a trascrivere integralmente, commentandoli con la consueta attenzione e la giusta distanza critica, $\mathrm{i}$ giudizi finora inediti dei Decreta pontifici, che rappresentano, in definitiva, l'envers curiale dell'indagine laica sulla letteratura; assurdo sarebbe un qualsiasi confronto tra $\mathrm{i}$ due versanti: tuttavia, l'impatto del divieto ecclesiastico sul pubblico di allora appare senz'altro più determinante delle pagine su Balzac di Sainte-Beuve o di Baudelaire. Infatti, indagando sulla diffusione delle traduzioni balzachiane in Italia, Stupazzoni tratteggia un grafico dall'andamento irregolare, la cui curva discendente a partire dal 1841 - anno in cui le otto opere balzachiane vennero inserite nell'Index - segnala con matematica precisione l'incidenza prodotta dal Decretum sull'editoria e sul pubblico dei lettori; basti dire che ancora nel 1864, il vescovo Baillès concludeva un nuovo Decretum 
relativo ad altri testi balzachiani con queste parole : «poiché tutte le opere di questo pessimo romanziere, sebbene morto quattordici anni fa, continuano a essere lette integralmente, vengono attentamente consultate, sono rilette e sconvolgono le menti di innumerevoli spose e non avvedute donne si corrompono i costumi. Di conseguenza, con vostro benevolo assenso, potrei affermare di ritenere che anche tutte le altre opere del medesimo autore devono essere condannate » (p. 175). 